Self-Regulation and Social Pressure Reduce Prejudiced Responding and Increase Motivation to be Non-Prejudiced Steven G. Buzinski

Department of Psychology \& Neuroscience, University of North Carolina, CB 3270, Chapel Hill, NC 27599

Michael B. Kitchens

Department of Psychology, Lebanon Valley College, 101 N. College Ave., Annville, PA 17003

Author Note

This manuscript contains 6,988 words (excluding title page and references).

Correspondence concerning this work should be addressed to Steven G. Buzinski, Department of Psychology \& Neuroscience, University of North Carolina at Chapel Hill, CB 3270, Chapel Hill, NC 27599. Email: buzinski@email.unc.edu 


\begin{abstract}
Self-regulation constrains the expression of prejudice, but when self-regulation falters, the immediate environment can act as an external source of prejudice regulation. This hypothesis derives from work demonstrating that external controls and internal self-regulation can prompt goal pursuit in the absence of self-imposed controls. Across four studies we found support for this complementary model of prejudice regulation. In Study 1, self-regulatory fatigue resulted in less motivation to be non-prejudiced, compared to a non-fatigued control. In Study 2, strong (vs. weak) perceived social pressure was related to greater motivation to be non-prejudiced. In Study 3, dispositional self-regulation predicted non-prejudice motivation when perceived social pressure was weak or moderate, but not when it was strong. Finally, in Study 4 self-regulatory fatigue increased prejudice when social pressure was weak but not when it was strong. Keywords: Self-Regulation, Social Pressure, Prejudice, Social Norms, Motivation
\end{abstract}




\section{Self-Regulation and Social Pressure Reduce Prejudiced Responding and Increase Motivation to be Non-Prejudiced}

Appropriate social functioning requires the awareness of a social standard and the necessary psychological resources to effectively modify behavior. In the present work we propose that these two processes—namely, salient social norms and self-regulation—act as complimentary mechanisms to regulate social behavior. One way that these processes may work together would be that social norms provide people with information about appropriate attitudes, and in turn, people use self-regulation to adhere to those standards. Following from this, people would be more likely to engage in self-regulation in the presence of social norms. Conversely, the process may work such that people use self-regulation to modify behavior, but when selfregulation resources are depleted, the pressure derived from salient social norms may act as an external source of constraint. The purpose of the present work was to test this latter prediction about how social norms and self-regulation work in tandem to engage effective regulation.

Prejudice provides a good test of this complimentary mechanism hypothesis because prejudice arises from basic and automatic processes (e.g., cognitive stereotypes; Fazio, Jackson, Dunton, \& Williams, 1995), but the expression of prejudice can be inhibited (Devine, 1989). Furthermore, the inhibition of prejudice relies upon both internal and external constraints (see Bodenhausen \& Richeson, 2010 and Fiske, 1998 for reviews). Specifically, research shows that the expression of prejudice changes as a function of two distinct and independent internal and external motivational systems (Plant \& Devine, 1998). The internal motivation to be nonprejudiced is analogous to intrinsic motivation, whereby the restraint of prejudicial responses relies on internal and well-developed self-regulation processes (see Legault, Green-Demers, \& Eadie, 2009). Conversely, the external motivation to be non-prejudiced arises from social 
constraints that inhibit prejudicial responding. Thus, the internal motivation to be non-prejudiced relies on self-regulation resources; whereas the external motivation to be non-prejudiced is facilitated by salient social norms against prejudice. The former, we contend, is more reliable and as such used to regulate prejudice; but when fatigued, the latter provides a mechanism by which the expression of prejudice can still be inhibited.

\section{Self-Regulation as an Internal Mechanism to Control Prejudice}

People primarily motivated by internal standards to be non-prejudiced are the least likely to exhibit prejudicial responses (Devine, Plant, Amodio, Harmon-Jones, \& Vance, 2002). This is because they have well-developed internal mechanisms that inhibit prejudicial responding. Specifically, they become sensitive to responses that do not adhere to their own non-prejudicial standards (e.g., by experiencing guilt), which then prompts the inhibition of subsequent prejudicial responses (Monteith, 1993; Monteith, Ashburn-Nardo, Voils, \& Czopp, 2002). Thus, critical to our prediction is that self-regulation is a key feature in inhibiting the expression of prejudice (see Butz \& Plant, 2009; also see Legault et al., 2009).

A large body of literature shows that self-regulation is required for appropriate functioning across a wide range of social behaviors (de Ridder, Lensvelt-Mulders, Finkenauer, Stok, \& Baumeister, 2012; DeWall, Baumeister, Gailliot, \& Maner, 2008; DeWall, Baumeister, Stillman, \& Gailliot, 2007; Tangney, Baumeister, \& Boone, 2004). Critically, though, according to the tenets of ego depletion theory, self-regulation becomes temporarily less likely to be effectively exerted after prior acts of self-regulation (see Baumeister, Bratslavsky, Muraven, \& Tice, 1998; Schmeichel \& Baumeister, 2004). This ego depletion pattern has been wellestablished in studies using a two-task paradigm (Hagger, Wood, Stiff \& Chatzisarantis, 2010; cf. Hagger \& Chatzisarantis, 2016). 
Seminal studies in this paradigm showed that participants who were assigned to eat radishes in the presence of tempting chocolate chip cookies persisted less on a subsequent figuretracing task than those who did not have to resist eating cookies (Baumeister et al, 1998), and that the inhibition of emotional responses to a distressing film caused people to spend less time squeezing a hand-grip device than those who had not previously regulated their emotional responses (Muraven, Tice, \& Baumeister, 1998). Researchers have also found this general pattern outside of the lab. Using an experience sampling method, Hofmann, Vohs, and Baumeister (2012) used smart phones to prompt participants to report whether they were currently experiencing a desire (e.g. to eat) and whether they attempted to, and were successful at, resisting that desire. The researchers found that the probability of resisting a particular desire was less if participants had recently resisted desires. In short, a wide range of experimental and non-experimental works show that self-regulation use produces subsequent behavior consistent with an inadequate application of self-regulation.

There are currently two competing theories attempting to explain these self-regulatory decrement effects. Ego-depletion theory proposes that self-regulation operates on a limited resource, and that the resource becomes expended by engaging in acts requiring self-regulation (Gailliot et al., 2007; Muraven \& Baumeister, 2000; Muraven et al., 1998). More recently, the Process Model of Self-Control (Inzlicht \& Schmeichel, 2012) has proposed that exercising selfregulation temporarily shifts attention and motivational resources away from effortful control and toward self-reward. These attentional and motivational states, then, and not a lack of selfregulation resources, are what cause people to engage in behaviors consistent with selfregulatory failure (Beedie \& Lane, 2012; Inzlicht \& Schmeichel, 2012; Schmeichel, HarmonJones, and Harmon-Jones, 2010). Our purpose in the present work was not to resolve these 
competing theories, nor to contribute evidence to the "limited resource" or "process" model of self-control. Instead, we are interested in their common prediction: that people demonstrate attitudes and behaviors indicative of reduced self-regulatory effectiveness after an initial use of self-control. In terms of the current work, that an initial exercise of self-regulation will result in failures to inhibit prejudice.

Indeed, this general prediction has been born out in previous research (e.g., Gaillot, Plant, Butz, \& Baumeister, 2007). Muraven (2008) found that initial acts of self-regulation resulted in subsequent prejudicial responses, and critically, that this was particularly true when nonprejudicial attitudes were less internalized (i.e., less internally-regulated; Govorun \& Payne, 2006; Legault et al., 2009). Based on this work, we predicted that exercising self-regulation would also result in subsequent changes in the motivation to be non-prejudiced.

\section{Social Norms as an External Mechanism to Control Prejudice}

Research also shows that external controls regulate behavior (Fishback \& Trope, 2005). Prejudice, for example, is influenced by interpersonal, social-constraints (Devine et al., 2002), and this is particularly true for those low in internal motivation - those with less developed internal mechanisms of control (Legault et al., 2009; Monteith et al., 2002; Zuwerink et al., 1996). As evidence of this, Devine, Monteith, Zuwerink, and Elliot (1991) found that those who were not motivated by internal standards to be non-prejudiced were more influenced by social standards than those who were motivated by internal standards. This body of work implies that social standards act as external constraints against prejudice, but do so particularly when internal mechanisms of regulation are weak.

Normative theories of behavior show that social norms influence a wide variety prosocial (e.g., Cialdini, Reno, \& Kallgren, 1973; Kallgren, Reno, \& Cialdini, 2000) and anti-social (e.g., 
Gino, Ayal, \& Ariely, 2009) behaviors. For example, Schultz, Nolan, Cialdini, Goldstein, and Griskevicius (2007) found that home owners consumed less energy when they were provided with information indicating that they had violated social norms of energy-conservation. In the same way, salient social norms provide relevant and influential information that regulates prejudicial responding (Amiot, Sansfacon, Louis, \& Yelle, 2012; Blanchard, Lilly, Vaughn, 1991; Monteith, Deneen, \& Tooman, 1996).

For example, Crandall, Eshleman, and O’Brien (2002) showed that people's perception of socially acceptable prejudices was correlated with prejudiced attitudes, indicating that normative information may influence prejudice — or at least, the expression of prejudice. Furthermore, researchers have found that experimental manipulations of normative information, wherein participants were led to believe that their peers had a relatively favorable or unfavorable impression of African Americans, caused participants to change their own attitudes about African Americans in commiserate ways (Stangor, Sechrist, \& Jost, 2001). Thus, in the present work, we relied upon the normative theory of social behavior in order to predict that antiprejudice social norms would influence the motivation to be non-prejudiced, particularly after a period of self-regulation exertion.

\section{The Present Work}

Previous research provides evidence that self-regulation and salient social norms inhibit prejudice responding. We use this context to test the hypothesis that these mechanisms work in tandem, such that when self-regulation is fatigued, salient social norms are effective at reducing prejudice. We conducted four studies that examined the influence of these variables on prejudice. Specifically, we manipulated self-regulation fatigue (Study 1 and Study 2) and measured perceived normative information (Study 2) to assess their influence on the motivation to be non- 
prejudiced. In the final two studies, we examined the interactive effect of dispositional (Study 3) and state (Study 4) self-regulation and normative information on prejudice, using self-report (Study 3) and behavioral (Study 4) measures.

\section{Study 1}

The purpose of this study was to determine the effect of self-regulatory fatigue on the expression of prejudice toward two minority groups: LGBT persons and African Americans. Fatigue was manipulated using a well validated story-writing manipulation (e.g., Schmeichel \& Vohs, 2009), and prejudice toward LGBT persons and African Americans was measured with the IMS-EMS for homosexuals and the Symbolic Racism 2000 scales, respectively. We predicted that the expression of prejudice toward LGBT persons and African Americans would be greatest when participants were fatigued.

\section{Participants}

Students $(N=40)$ from a small, liberal arts college in the northeast region of the United States participated in exchange for partial research credit. The final sample $\left(15\right.$ females; $M_{a g e}=$ 19.70; $\left.S D_{\text {age }}=3.44\right)$ primarily identified as Caucasian $(90.0 \%$, with $2.5 \%$ African American, 5.0 $\%$ Hispanic, and $2.5 \%$ other) and heterosexual (95.0\%, with $2.5 \%$ homosexual, and $2.5 \%$ bisexual).

\section{Materials and Procedure}

Participants completed Study 1 in a research laboratory. They were led to believe that the study's purpose was to evaluate how thoughts and attitudes affect cognitive processes. After completing consent and demographics forms, participants underwent a standard self-regulation fatigue task (e.g., Schmeichel \& Vohs, 2009). Participants were randomly assigned to spend seven minutes writing a story about a recent trip without using any words containing the letters 
"a" or "n," or to write the story without any restrictions. Greater self-control was required in the

former than the latter condition in order to successfully regulate one's writing. Afterwards, participants rated this task's difficulty using a 1 (not difficult at all) to 10 (extremely difficult)

Likert scale.

After the self-regulatory fatigue manipulation, participants completed the SR2000 ( $\alpha=$ .67), a standardized measure of prejudice towards African Americans, and the IMS-EMS ${ }^{1}$ for homosexuals (IMS $\alpha=.77$ ), which measures internal and external motivation to be nonprejudiced towards LGBT persons. All scales were counterbalanced in order to prevent order effects. Finally, participants were checked for suspicion, fully debriefed, and then thanked for their participation.

\section{Results}

Accuracy Check. We first checked on the extent to which participants followed directions on the self-regulatory fatigue task by analyzing their stories for adherence to instructions. The unregulated writing condition was not tasked with a special rule set, so their stories were simply checked for completion. All participants in the unregulated writing condition completed the story writing task, and all participants in the regulated writing condition completed the story writing task while adhering to the given instructions.

Manipulation Check. In order to check the effectiveness of the self-regulatory fatigue manipulation, we conducted a one-way analysis of variance (ANOVA) on participants' perception of the writing task's difficulty. Participants in the fatigued condition $(M=8.58, S D=$

\footnotetext{
${ }^{1}$ We have not included analysis of EMS scores because they are not of theoretical interest to the current investigation. The IMS measures an internal, values-based motivation to be non-prejudiced; whereas, the EMS measures an external, image-concerned motivation to appear non-prejudiced (e.g., Item 3: "I try to hide any negative thoughts about homosexuals in order to avoid negative reactions from others;" also see Devine et al., 2002). Thus, the IMS is more likely to be influenced by a deficit in the type of internal prejudice control factor (self-regulation) that we have detailed. As such, we believe that the IMS is a more accurate measure of our construct of interest.
} 
0.45) rated the task as significantly more difficult than the participants in the non-fatigued condition $(M=2.05, S D=0.44), F(1,37)=107.03, p<.01$, indicating that the manipulation was successful.

Prejudice Analysis. To investigate the influence of our experimental conditions on the expression of prejudice, parallel one-way univariate ANOVAs were conducted. The results revealed a significant effect on internal motivation to be non-prejudiced toward homosexuals, $F(1,38)=9.38, p=.004, \eta^{2}=.20$, but not on African American prejudice, $F(1,38)=1.21, p=$ $.27, \eta^{2}=.03$. As seen in Figure 1, participants were less internally motivated to be nonprejudiced in the self-regulatory fatigue condition $(M=6.21, S D=1.35,95 \% \mathrm{CI}[5.56,6.86])$ than in the non-fatigued condition $(M=7.50, S D=1.32,95 \%$ CI $[6.91,8.10])$. Participants in the fatigue and non-fatigued conditions demonstrated equal prejudice toward African Americans.

\section{Discussion}

Study 1 provided initial support for our complementary-factors hypothesis, but the results revealed only one of the two predicted effects of self-regulatory fatigue. Self-regulatory fatigue reduced participants' internal motivation to be non-prejudiced towards LGBT persons. It did not affect prejudice towards African Americans. We believe that this is likely due to the measured used in Study 1. In hindsight, use of the SR2K scale in Study 1 was problematic because it measures prejudicial attitudes toward African Americans, whereas the IMS measures the motivation to be non-prejudiced. It is possible that self-regulatory fatigue influences motivations more readily than attitudes. To improve comparability across groups and the generalizability of our findings, we have utilized similar motivational measures in subsequent studies.

\section{Study 2}


The purpose of this study was to determine the effect of self-regulatory fatigue and perceived pressure to be non-prejudiced on the motivation be non-prejudiced. Similar to Study 1 , fatigue was manipulated using a well validated story-writing manipulation (e.g., Schmeichel \& Vohs, 2009). Social pressure to be non-prejudiced was measured, and the motivation to be nonprejudiced was measured with the IMS-EMS (Plant \& Devine, 1998). We predicted that selfregulatory fatigue would diminish non-prejudice motivation when perceived social pressure to be non-prejudiced was low but not when it was high.

\section{Participants}

Online members $(N=171)$ of Amazon's Mechanical Turk platform participated in exchange for $\$ 0.75$. One participant chose not to participate after the consenting process, and thus did not complete the experiment. The final sample $\left(N=170 ; 90\right.$ females; $M_{\text {age }}=37.65$; $\left.S D_{\text {age }}=12.82\right)$ primarily identified as Caucasian $(81.2 \%$, with 6.5\% Asian, $4.7 \%$ African American, $4.1 \%$ Hispanic, and 3.5\% other) and heterosexual (84.7\%, 10.6\% bisexual, 3.5\% homosexual, and $1.2 \%$ asexual). All participants were residents of the United States of America.

\section{Materials and Procedure}

Participants completed Study 2 online. They were led to believe that the study's purpose was to evaluate how attitude characteristics are related to verbal and cognitive fluency. After completing a consent form, participants completed an ostensible "verbal and cognitive fluency" task. This task was actually the self-regulatory fatigue manipulation used in Study 1 (Schmeichel \& Vohs, 2009), wherein participants were randomly assigned to spend seven minutes writing a story about a recent trip with restrictive rules (cannot use words containing the letters ' $a$ ' and ' $n$ ') or without rules (can use any word). Afterwards, participants rated the task's difficulty using a 1 (very difficult) to 7 (very easy) Likert scale. 
Next, participants were led to believe that the psychometric properties of the forthcoming attitude assessment required a "neutral affective state." Therefore, they would have to sit and rest for a period of time before moving on. During that rest period participants were shown a screen asking them to help with a supposedly unrelated research project. After clicking through to the next screen, they were randomly assigned to complete a one-item measure of perceived social pressure to be non-prejudiced toward LGBT persons or African Americans (i.e., "How much social pressure do you think there is in the United States to be accepting of [GROUP].”), and then the IMS-EMS ${ }^{2}$ for their assigned group.

Both groups were included in order to increase the external validity of this research, but our aim was not to contrast the extent or direction of prejudice toward these groups. Prejudice toward LGBT persons and African Americans varies in meaningful ways, and we do not wish to flatten those distinctions. Rather, we are interested in examining the potential roles of social pressure and self-regulation in constraining prejudice across many groups. Therefore, after checking to ensure that there were no significant differences in perceived social pressure or IMS means between the LGBT and African American groups (there were not; all $F$ s $<1.25$ ), we collapsed the two groups into one. This resulted in our obtaining one perceived social pressure to be non-prejudiced score, and an internal motivation to be non-prejudiced mean (IMS $\alpha=.90$ ).

After completing the IMS-EMS, participants completed a demographics form described as the general attitudes measure, followed by a suspicion check and full debrief. Finally, participants were thanked for their assistance and provided with a pay code to be entered into Mechanical Turk.

\section{Results}

\footnotetext{
${ }^{2}$ As in Study 1, IMS and not EMS scores were analyzed and reported.
} 
Accuracy Check. As in Study 1, we checked on the extent to which participants followed directions on the self-regulatory fatigue task by analyzing their stories for adherence to instructions. All participants in the unregulated writing condition completed the story writing task. Unfortunately, the instructions (i.e., write for seven minutes and do not use any words containing the letters 'a' or ' $n$ ') were only followed by $29.30 \%$ of participants in the regulated writing condition. Because the majority of participants in the regulated writing condition did not adhere to our instructions, we cannot be confident that the self-regulatory fatigue manipulation was successful. Therefore, we only analyzed the influence of perceived social pressure to be nonprejudiced on the expression of prejudice in the following analyses.

Prejudice Analysis. We first conducted a split-half analysis on perceived social pressure to be non-prejudiced in order to create low and high perceived pressure groups. These groups served as a categorical predictor variable. Next, we conducted a one-way ANOVA in order to investigate the relationship between perceived social pressure to be non-prejudiced and the expression of prejudice. Results revealed the predicted effect of perceived social pressure on internal motivation to be non-prejudiced, $F(1,168)=47.45, p<.001, \eta^{2}=.22$. Participants were less internally motivated to be non-prejudiced when social pressure was perceived as low $(M=$ $5.87, S D=2.15,95 \% \mathrm{CI}[5.44,6.30])$ than when it was perceived as high $(M=7.79, S D=1.48$, 95\% CI [7.45, 8.13]). Means are shown in Figure 2.

\section{Discussion}

Study 2 provided support for the external control aspect of our predictions, in that differences in perception of social pressure (an external factor) were related to internal motivation to be non-prejudiced. Specifically, compared to a greater perceived social pressure group, the perception of weak social pressure to be non-prejudiced was related to less internal 
motivation to be non-prejudiced. Study 2, like Study 1, supports half of our complementaryfactors hypothesis. In order to extend these findings, and to probe our proposed interaction, Study 3 examined the joint influence of dispositional self-regulation and perceived social pressure to be non-prejudiced on the expression of prejudice.

\section{Study 3}

The purpose of this study was to determine the effect of dispositional self-regulation and perceived pressure to be non-prejudiced on the expression of prejudice. Dispositional selfregulation was measured using the Brief Self-Control Scale (Tangney, et al. 2004), perceived social pressure to be non-prejudiced was measured using a one-item scale, and the motivation to be non-prejudiced was measured with the IMS-EMS (Plant \& Devine, 1998). We predicted that dispositional self-control would be related to the expression of prejudice when perceived social pressure to be non-prejudiced was low or moderate, but not when it was high.

\section{Participants}

Online members $(N=191)$ of Amazon's Mechanical Turk platform participated in exchange for $\$ 0.80$. Recruitment was limited to members residing in the United States of America, and the final sample (100 females; $\left.M_{a g e}=36.81 ; S D_{a g e}=12.56\right)$ primarily identified as Caucasian (75.8\%, with 7.9\% African American, 7.9\% Asian, 3.2\% Hispanic, and 5.2\% other) and heterosexual $(89.5 \%, 5.2 \%$ bisexual, $3.1 \%$ homosexual, and $2.2 \%$ other).

\section{Materials and Procedure}

Participants completed Study 3 online. They were led to believe that the study's purpose was to evaluate how psychological dispositions were related to attitudes and beliefs. After completing a consent form, they were told that they would complete several questionnaires measuring dispositions and attitudes, beliefs, and behaviors. These questionnaires consisted of 
the Brief Self-Control Scale (Tangney, et al. 2004), the one-item measure of perceived social pressure to be non-prejudiced used in Study 2, and the IMS-EMS ${ }^{3}$ (Plant \& Devine, 1998). Questionnaires were counter-balanced in order to prevent order effects. Similar to Study 2, participants were randomly assigned to complete the social pressure item and IMS-EMS about LGBT persons or African Americans. This was done to increase external validity and to provide evidence for the domain-generality of social pressure and self-regulation in the expression of prejudice.

After checking to ensure that there were no significant differences in perceived social pressure or IMS means between the LGBT and African American groups (all $F_{\mathrm{S}}<1.1$ ), we collapsed across groups. This resulted in our obtaining a perceived social pressure to be nonprejudiced score, an internal motivation to be non-prejudiced mean (IMS $\alpha=.86$ ), and a dispositional self-regulation mean (BSCS $\alpha=.91$ ), for every participant. Finally, participants completed a demographics form, were checked for suspicion, debriefed, provided a pay code for Mechanical Turk, and thanked for their participation.

\section{Results}

Prejudice Analysis. We tested a multiple regression model to investigate whether the association between dispositional self-regulation and internal motivation be non-prejudiced depends on the level of perceived social pressure to be non-prejudiced. After centering dispositional self-regulation and perception of social pressure to be non-prejudiced, and computing the self-regulation-by-perceived social pressure interaction term (e.g., Aiken \& West, 1991), we entered the two predictors and interaction term into a simultaneous regression model. The omnibus model explained a significant proportion of variance, $F(3,187)=20.18, p<.001$,

\footnotetext{
${ }^{3}$ As in Studies 1 and 2, IMS and not EMS scores were analyzed and reported.
} 
$R^{2}=.25, R_{\text {adjusted }}^{2} .23$. Self-regulation $\left(\mathrm{b}=.50, \mathrm{SE}_{\mathrm{b}}=.15, t=3.33, p<.001\right)$ and perceived social pressure to be non-prejudiced $\left(\mathrm{b}=.51, \mathrm{SE}_{\mathrm{b}}=.07, t=6.98, p<.001\right)$ were found to be positively associated with internal motivation to be non-prejudiced. Most critically for our prediction, the interaction was also significant $\left(\mathrm{b}=-.21, \mathrm{SE}_{\mathrm{b}}=.10, t=-2.17, p=.03\right)$, suggesting that the association between self-regulation and prejudice depends on the extent of perceived social pressure to be non-prejudiced.

We conducted simple slopes analyses to probe this interaction. Simple slopes for the association between self-regulation and internal motivation to be non-prejudiced were tested at low (-1 SD below the mean), moderate (at the mean), and high (+1 SD above the mean) levels of perceived social pressure. As seen in Figure 3, this analysis revealed a significant positive association between self-regulation and internal motivation to be non-prejudiced at low ( $\mathrm{b}=.85$, $\left.\mathrm{SE}_{\mathrm{b}}=.19, t=3.90, p<.001\right)$ and moderate $\left(\mathrm{b}=.50, \mathrm{SE}_{\mathrm{b}}=.15, t=5.33, p<.001\right)$, but not at high $\left(\mathrm{b}=.15, \mathrm{SE}_{\mathrm{b}}=.18, t=0.11, p=.91\right)$ levels of perceived social pressure.

\section{Discussion}

Study 3 provided support for the interactive nature of our complementary-factors hypothesis of prejudice regulation. Dispositional self-regulation was positively related to internal motivation to be non-prejudiced at low and moderate, but not high, levels of perceived social pressure. In terms of our predictions, internal factors (self-regulation) are relied upon to constrain prejudice when external factors (perceived social pressure) are weaker, but are no longer required when those external factors are strong. These findings suggest that self-regulation and perceived social pressure to be non-prejudiced may lead to the adoption of non-prejudiced values. Ultimately, our goal is to support this causal pathway, but Study 3 employed correlational rather than experimental methods. Consequently, we conducted a fourth study in 
which we experimentally manipulated self-regulation as well as perceived social pressure, and measured prejudice.

\section{Study 4}

Study 4 tested the causal role of self-regulatory fatigue and the perception of social pressure to be non-prejudiced in the regulation of prejudice. Since people tend to mask or suppress overt prejudicial behavior, we utilized a covert measure of prejudice. After being presented with information about LGBT issues, participants were offered a plate of cookies and were asked to sanitize their hands with hand sanitizing liquid before indulging. The amount of hand sanitizer used was measured and served as an indication of homosexual prejudice since hand cleansing has been linked with prejudice (see Huang, Sedlovskaya, Ackerman, \& Bargh, 2011). We predicted that high social pressure would moderate the effect of self-regulation fatigue on the expression of prejudice, such that participants in the fatigue conditions would use more hand sanitizer than participants in the non-fatigued conditions under a low, but not high, social pressure to be non-prejudiced condition.

\section{Participants}

Students $(N=95)$ from a small liberal arts college in the Northeast region of the United States participated in exchange for partial course credit or extra credit. Two participants were excluded from the analysis because they used hand-sanitizer multiple times before being presented with the cookies and one participant because the amount of hand-sanitizer used was identified as an outlier (> $3 S D$ s above the mean). The final sample $\left(N=92 ; 70\right.$ females; $M_{\text {age }}=$ 19.82, $\left.S D_{\text {age }}=1.11\right)$ primarily identified themselves as Caucasian $(83.7 \%$, with $7.6 \%$ Hispanic, $3.3 \%$ African American, and 5.4\% other), heterosexual (97.8\%, with 2.2\% bisexual), and Christian/Catholic (89.1\%). 


\section{Materials and Procedure}

Participants individually arrived for the laboratory session and were led to believe that the purpose of the study was to investigate the relationship between cognitive skills and personality. After completing the consent form they were provided with the first task, which was described as a cognitive skills assessment. In reality, the task was a manipulation of selfregulatory fatigue (e.g., Tice, Baumeister, Shmueli, \& Muraven, 2007). Participants initially identified and crossed-out any instance of the letter $e$ in a page-length text from a statistics book. Next, participants were randomly assigned to either complete the same task on another passage, or cross out all instances of the letter $e$ unless it appeared next to or one letter away from another vowel. Greater self-control was required in the latter condition because participants were required to regulate their responses to come in line with the new rule set.

Next, participants were led to believe that the psychometric properties of the personality assessment required a "neutral affective state," and thus, they would have to sit and rest for a period of time before moving on. During this break, the undergraduate research assistant, pulling a survey from her backpack, serendipitously asked participants if they would complete a Department of Psychology survey that she had to administer for a class project. The survey contained a brief explanation for the two questions that were asked on the survey. This explanation served as the manipulation of social pressure to be non-prejudiced. In the low social pressure condition, participants read:

Every year, XXXXXXXXX College requests that each department survey[s] a portion of our students in order to document the ever-changing beliefs of the student body on a range of topics. One particular questionnaire asked about opinions regarding Lesbian, Gay, Bisexual, and Transgender (LGBT) persons. 
Based on results from early in the semester, we have found that a few of XXXXXXXXX College students (11\%) fall into the "high-tolerance" category regarding their attitude toward LGBT individuals. This means they find it personally important to avoid feelings prejudice attitudes and displaying prejudice behavior toward such individuals.

In the high social pressure condition, participants read:

Every year, XXXXXXXXX College requests that the each department survey[s] a portion of students in order to document the ever-changing beliefs of the student body on a range of topics. One particular questionnaire asked about opinions regarding Lesbian, Gay, Bisexual, and Transgender (LGBT) persons. Based on results from early in the semester, we have found that most XXXXXXXXX College students (89\%) fall into the "high-tolerance" category regarding their attitudes toward LGBT individuals. This means they find it personally important to avoid feeling prejudice attitudes and displaying prejudice behavior toward such individuals.

Participants then responded to the two questions on the survey. First, they rated the extent to which they were surprised they were by these findings on a scale from 1 (not at all surprised) to 7 (very surprised) based on their experiences on campus. Second, they rated the extent to which they thought the findings were accurate on a scale from 1(not at all accurate) to 7 (very accurate).

After responding to the survey, the participants were told that they had a few more minutes to wait until the personality assessment could be administered. They were, then, offhandedly, offered a plate of cookies that were purportedly left over from a research meeting. 
Before eating, however, they were asked to use hand-sanitizer to prevent the spread of germs. The amount of hand sanitizer used served as the dependent measure of prejudice. The rationale for this comes from research demonstrating a relationship between prejudice toward an outgroup and the phenomenological experience of disgust (Hodson \& Costello, 2007). The experience of disgust, in turn, has been shown to produce a need for cleanliness (Lee \& Schwartz, 2010), and sanitizing hands reduced negative attitudes towards prejudice (Huang et al., 2011).

Finally, participants rated the difficulty of the cognitive perception task (the selfregulatory fatigue manipulation) on a scale from 1 (not difficult at all) to 10 (extremely difficult) and completed a demographics survey. The debriefing session included questions about their understanding of the purpose of the study to probe for suspicion and their memory of the percentage cited in the passage about the LGBT community.

\section{Results}

Manipulation Checks. The self-regulatory fatigue manipulation was effective. Participants rated the self-regulatory fatigue task $(M=4.62, S D=1.86)$ as more difficult than the non-fatigued task $(M=3.42, S D=2.11), t(90)=2.89, p=.005$, and, consistent with studies on ego depletion (Baumeister et al., 1998), participants in the fatigue condition ate more cookies $(M=1.04, S D=1.68)$ than participants in the non-fatigued condition $(M=0.60, S D=0.69)$, $t(61.52)=1.67, p=.10($ adjusted for unequal variance $)$

It was also important to determine whether participants noticed the social pressure manipulation embedded in the survey, so during the debriefing participants were asked the percentage of individuals reported as "highly tolerant" on the survey. Participants in both the low $(11 \%)$ and high $(89 \%)$ social pressure conditions accurately recalled the percentage of 
people described as highly tolerant $(M=11.07$, Range $=10-15$ and $M=88.20$, Range $=78-95$ respectively).

Participants were also asked to report how surprised they were by the survey's findings and how accurate they thought the results were. These ratings were negatively correlated with each other $(r=-.67, p<.001)$, such that the more surprised participants were, the less accurate that they perceived the results to be. The participants in the non-fatigued condition $(M=3.60$, $S D=1.48)$ were marginally more surprised than participants in the fatigue condition $(M=3.34$, $S D=1.66), F(1,88)=3.38, p=.06$, and those in the low social pressure condition $(M=4.15, S D$ $=1.52)$ were more surprised than those in the high social pressure condition $(M=2.78, S D=$ 1.32), $F(1,88)=24.52, p<.001$. There was no interaction $F<1, n s$.

Participants in the low social pressure condition believed the findings were less accurate $(M=4.09, S D=1.21)$ than those in the high social pressure condition $(M=4.98, S D=1.33)$, $F(1,88)=11.94, p=.001$. There was no effect of self-regulatory fatigue on accuracy, or an interaction $F \mathrm{~s}<1, n s$.

Prejudice Analysis. To determine whether these conditions influenced the extent to which participants expressed prejudice through the use of hand-sanitizer, a 2 Self-Regulatory Fatigue $x 2$ Social Pressure ANCOVA was conducted. Since the use of hand-sanitizer was linked with the intake of cookies, we analyzed these data with cookies entered as the covariate. The homogeneity assumption was met, $F(3,88)=1.50, p=.22$, and cookie intake significantly predicted the use of hand-sanitizer, $F(1,87)=27.63, p<.001$. There were no main effects, $F \mathrm{~s}<$ $1, n s$, but the predicted interaction was statistically significant, $F(1,87)=4.51, p=.03, \eta^{2}=.05$ (see Figure 1). 
Simple effects analysis revealed an unexpected but marginally significant effect in which non-fatigued participants used more hand sanitizer than fatigued participants in the high social pressure conditions, $p=.06, \eta^{2}=.04$ but there was no difference between non-fatigued and fatigued participants in the in the low social pressure conditions, $p=.26, \eta^{2}=.01$. Most critical for our predictions, fatigued participants used more hand sanitizer when they were in the low social pressure context $(M=0.22, S E=0.05,95 \% \mathrm{CI}[0.13,0.32])$ than in the high social pressure context $(M=0.07, S E=0.06,95 \% \mathrm{CI}[-0.04,0.18]), p=.04, \eta^{2}=.05$. There was no difference in hand sanitizer use across non-fatigued participants, regardless of whether they were in a high $(M=0.21, S E=0.05,95 \% \mathrm{CI}[0.11,0.30])$ or low social pressure condition $(M=0.14$, $S E=0.06,95 \%$ CI $[0.02,0.25]), p=.33, \eta^{2}=.01$.

\section{Discussion}

Study 4 showed that self-regulation fatigue resulted in greater prejudice, but only when social pressure to be non-prejudiced was minimal. This-like previous research (Muraven, 2008; Govorun \& Payne, 2006)—showed that self-regulation fatigue increases prejudice responding, but consistent with our predictions, this effect was moderated by introducing anti-prejudice norms. Study 4 also added to the previous studies by going beyond self-report measures of motivation. This provides greater external validity and responds to the need for greater behavioral observations in psychological research (Baumeister, Vohs, \& Funder, 2007). Behavioral measures of prejudice are challenging because people can easily mask such socially undesirable acts. As such, the hand-sanitizer measure was particularly good at utilizing behavioral measures and maintaining a covert assessment of prejudice. The rationale for this measure is supported by research that shows a relationship between the experience of disgust and prejudice against out-groups (Hodson \& Costello, 2007) and research that shows reminders 
about cleanliness lead people to make harsher judgments about sexual impurity (Helzer \& Pizarro, 2011). As such, we expected that thinking about homosexuals would cause participants to use more hand-sanitizer.

In all, Study 4, in conjunction with the previous studies, provides a consistent pattern in which self-regulation fatigue and salient social norms influence prejudice. More specifically, this pattern suggests that these two processes work in tandem, such that, self-regulation resources are needed to reduce prejudice in the absence of salient social norms against prejudice, as was demonstrated in Study 4.

\section{General Discussion}

The purpose of the present work was to examine whether self-regulation and perceived anti-prejudice social norms regulated prejudice. Based on ego depletion theory and normative theories of social behavior, we expected that these variables would act in a complimentary fashion to reduce prejudicial responding. Specifically, we predicted that when self-regulation was fatigued, the presence of external constraints - in the form of salient anti-prejudice normswould prompt people to inhibit prejudiced responding (e.g., Fishbach \& Trope, 2005). We found support for this hypothesized process across four studies. Experimentally inducing selfregulatory fatigue reduced internal motivation to be non-prejudiced (Study 1), and perceived anti-prejudice social norms predicted internal motivation to be non-prejudiced (Study 2). Thus, both factors had independent effects on prejudice in the predicted direction. Study 3 demonstrated their interactive nature; showing that dispositional self-regulation predicted greater internal motivation to be non-prejudiced, but importantly, only when anti-prejudice social norms were perceived to be relatively weak. Study 4 extended these findings by utilizing experimental manipulations of self-regulatory fatigue and anti-prejudice social norms. As expected, the results 
showed that self-regulatory fatigued participants exhibited less prejudice when the social pressure to be non-prejudiced was high, than when it was low. Also as predicted, there was no difference in prejudice across social pressure when self-regulation was not fatigued.

Across the four studies, we attempted to increase the methodological soundness of our investigation, and confidence in our conclusions, by employing converging methodologies. We exploited both measurements and manipulations of self-regulation and social norms; utilized well-validated measures of non-prejudice motivation, as well as a behavioral measure of prejudice; conducted the research with diverse participant samples (i.e., Mechanical Turk workers, college students); and used correlational and experimental research designs. Taken together, these results provide converging and robust support for the complementary nature of self-regulation and social norms in prejudice regulation.

Our findings also complement an existing body of literature related to self-regulation. Specifically, we based our predictions on ego depletion theory: that an initial exertion of selfregulation causes subsequent self-regulatory decrements (see Baumeister et al., 1998; Schmeichel \& Baumeister, 2004). We predicted that those decrements would take the form of demonstrably diminished non-prejudice motivation and increased prejudice. As a whole, we found effects that were broadly consistent with ego depletion theory (Gaillot et al., 2007; Muraven, 2008). For example, self-regulatory fatigued participants reported less non-prejudice motivation than non-fatigued participants (Study 1), and fatigued participants demonstrated more prejudice in the absence (vs. presence) of strong social norms against prejudice (Study 4). Our findings did not provide unequivocal support for ego depletion theory, however. We were unable 
to successfully manipulate ego depletion in Study $2^{4}$, and we did not observe an overall main effect consistent with ego-depletion theory's predictions in Study 4.

As noted previously, the mechanism by which the ego depletion effect occurs has traditionally been attributed to the diminishment of a general self-control "resource" (e.g., Baumeister et al., 1998; Schmeichel \& Baumeister, 2004), such as blood glucose (e.g., Gailliot \& Baumeister, 2007; Gailliot et al., 2007). More recently, the process model of self-control has proposed that the self-regulatory decrements observed in ego depletion studies are due to shifts in attention and motivation (Beedie \& Lane, 2012; Inzlicht \& Schmeichel, 2012). While the current work does not contribute evidence to either the resource or process model explanation, it does suggest an interesting possible direction for future research. Namely, by utilizing motivational dependent measures, such as the IMS, and resource measures, such as blood glucose, future researchers may be able to further unpack the mechanism underlying ego depletion effects. This would help to clarify the process vs. resource debate in the broader selfcontrol literature.

When considering the contributions of the present work, it is also important to consider the role of internal and external motivations to be non-prejudiced. Devine et al.'s (2002) model provides different predictions under which conditions people engage in prejudice. For example, internally, but not externally, motivated individuals respond to their own prejudiced responses by activating self-regulatory processes and self-correcting (Monteith, 1993); and internal, but not external, motivation is associated with greater stereotype rejection (Fehr, Sassenberg, \& Jonas, 2012; Legault et al., 2009). These findings indicate that internal motivation to be non-prejudiced

\footnotetext{
${ }^{4}$ We do not have empirical evidence to support our assertion, but we believe that the failure to manipulate ego depletion in Study 2 was likely caused by the combination of its online environment and our failure to strongly impress upon participants the importance of following the intricate directions for the ego depletion task.
} 
is a good approximation of one's genuine attitudes regarding prejudice, which is what we sought to investigate. It also suggests that predictions about the processes involved in regulating prejudice may depend on one's prior motivations to control prejudice—-something that we did not consider in the present work.

This is important to note for two reasons. First, our findings supported our hypothesis, irrespective of pre-existing variations in internal and external motives to be non-prejudiced. This suggests that, despite the influence dispositional motivations have for the extent to which people respond with or without prejudice, self-regulation and social norms still influence prejudice in systematic ways, consistent with our predictions. Second, the current findings raise another intriguing direction for future research. That is, taking such individual differences into account should yield additional predictions that will account for crucial variance in the regulation of prejudice.

\section{Summary and Conclusion}

The present work tested the extent to which intrapersonal self-regulation processes and interpersonal anti-prejudice social norms influenced the expression of prejudice. We found that these processes work in tandem, such that people rely on self-regulation when anti-prejudice social norms are weak or non-present, but that strong anti-prejudice social norms reduce prejudice when self-regulation falters. These studies provide empirical support for intra- and inter- personal accounts of prejudice regulation that fits with the larger literature on prejudice (Bodenhausen \& Richeson, 2010; Fiske, 1998). 


\section{References}

Aiken, L. S., \& West, S. G. (1991). Multiple regression: Testing and interpreting interactions. Thousand Oaks: Sage.

Alberts, H. J. E. M., Martijn, C., \& de Vries, N. K. (2011). Fighting self-control failure:

Overcoming ego depletion by increasing self-awareness. Journal of Experimental Social Psychology, 47, 58-62. doi: 10.1016/j.jesp.2010.08.004

Amiot, C. E., Sansfacon, S., Louis, W. R., \& Yelle, M. (2012). Can intergroup behaviors be emitted out of self-determined reasons? Testing the role of group norms and behavioral congruence in the internalization of discrimination and parity behaviors. Personality and Social Psychology Bulletin, 38, 63-76. doi: 10.1177/0146167211429804

Baumeister, R. F., Bratslavsky, E., Muraven, M., \& Tice, D. M. (1998). Ego depletion: Is the active self a limited resource? Journal of Personality and Social Psychology, 74, 12521265. doi: 10.1037/0022-3514.74.5.1252

Baumeister, R. F., \& Vohs, K. D. Self-regulation, ego depletion, and motivation. Social and Personality Psychology Compass, 1. doi: 10.1111/j.1751-9004.2007.00001.x.

Baumeister, R. F., Vohs, K. D., \& Funder, D. C. (2007). Psychology as the science of selfreports and finger movements: Whatever happened to actual behavior? Perspectives on Psychological Science, 2, 396-403.

Beedie, C. J., \& Lane, A. M. (2012). The role of glucose in self-control: Another look at the evidence and an alternative conceptualization. Personality and Social Psychology Review, 16, 143-13. doi: 10.1177/1088868311419817

Blanchard, F. A., Lilly, T., \& Vaugh, L. A. (1991). Reducing the expression of racial prejudice. Psychological Science, 2, 101-105. doi: 10.1111/j.1467-9280.1991.tb00108.x 
Bodenhausen, G. V., \& Richeson, J. A. (2010). Prejudice, stereotyping, and discrimination. In R. F. Baumeister \& E. J. Finkel (Eds.), Advanced social psychology: The state of the science (pp. 341-383). Oxford University Press: Oxford.

Butz, D. A., \& Plant, E. A. (2009). Prejudice control and interracial relations: The role of motivation to respond without prejudice. Journal of Personality, 77, 1311-1342. doi: 10.1111/j.1467-6494.2009.00583.x

Cialdini, R. B., Reno, R. R., \& Kallgren, C. A. (1973). A focus theory of normative conduct: Recycling the concept of norms to reduce littering in public places. Journal of Personality and Social Psychology, 58, 1015-1026. doi: 10.1037/0022-3514.58.6.1015

Crandall, C. S., Eshleman, A., \& O’Brien, L. (2002). Social norms and the expression and suppression of prejudice: The struggle for internalization. Journal of Personality and Social Psychology, 82, 359-378. doi: 10.1037//0022-3514.82.3.359

de Ridder, D. T. D., Lensvelt-Mulders, G., Finkenauer, C., Stok, F. M., \& Baumeister, R. F. (2012). Taking stock of self-control: A meta-anlaysis of how trait self-control relates to a wide range of behaviors. Personality and Social Psychology Review, 16, 76-99. doi: $10.1177 / 1088868311418749$

DeWall, C. N., Baumeister, R. F., Stillman, T. F., \& Gailliot, M. T. (2007). Violence restrained: Effects of self-regulation and its depletion on aggression. Journal of Experimental Social Psychology, 43, 62-76. doi: 10.1016/j.jesp.2005.12.005

DeWall, C. N., Baumeister, R. F., Gailliot, M. T., \& Maner, J. K. (2008). Depletion makes the heart grow less helpful: Helping as a function of self-regulatory energy and genetic relatedness. Personality and Social Psychology Bulletin, 34, 1653-1662. doi: $10.1177 / 0146167208323981$ 
Devine, P. G. (1989). Stereotypes and prejudice: Their automatic and controlled components. Journal of Personality and Social Psychology, 56, 5-18. doi: 10.1037/0022-3514.56.1.5

Devine, P. G., Plant, E. A., Amodio, D. M., Harmon-Jones, E., \& Vance, S. L. (2002). The regulation of explicit and implicit racial bias: The role of motivations to respond without prejudice. Journal of Personality and Social Psychology, 82, 835-848. doi:

$10.1037 / / 0022-3514.82 .5 .835$

Fazio, R. H., Jackson, J. R., Dunton, B. C., \& Williams, C. J. (1995). Variability in automatic activation as an unobtrusive measure of racial attitudes: A bona fide pipeline? Journal of Personality and Social Psychology,69, 1013-1027. doi: 10.1037/0022-3514.69.6.1013

Fehr, J., Sassenberg, K., \& Jonas, K. J. (2012). Willful stereotype control: The impact of internal motivation to respond without prejudice on the regulation of activated stereotypes. Zeitschrift für Psychologie, 220, 180-186. doi: 10.1027/2151-2604/a000111

Fishbach, A., \& Trope, Y. (2005). The substitutability of external control and self-control. Journal of Experimental Social Psychology, 41, 256-270. doi: 10.1016/j.jesp.2004.04.002

Fiske, S. T. (1998). Stereotyping, prejudice, and discrimination. In D. T. Gilbert, S. T. Fiske, \& G. Lindzey (Eds.), The handbook of social psychology $\left(4^{\text {th }}\right.$ ed, Vol. 2, pp. 357-411). McGraw-Hill: New York.

Gailliot, M. T., \& Baumeister, R. F. (2007). The physiology of willpower: linking blood glucose to self-control. Personality and Social Psychology Review, 11, 303-327. doi: $10.1177 / 1088868307303030$

Gailliot, M. T., Baumeister, R. F., DeWall, C. N., Maner, J. K., Plant, A., Tice, D. M., Brewer, L. E., \& Schmeichel, B. J. (2007). Self-control relies on glucose as a limited energy 
source: Willpower is more than a metaphor. Journal of Personality and Social Psychology, 92, 325-336. doi: 10.1037/0022-3514.92.2.325

Gailliot, M. T., Plant, E. A., Butz, D. A., \& Baumeister, R. F. (2007). Increasing self-regulatory strength can reduce the depleting effect of suppression stereotypes. Personality and Social Psychology Bulletin, 33, 281-294. doi: 10.1177/0146167206296101

Gino, F., Ayal, S., \& Ariely, D. (2009). Contagion and differentiation of unethical behavior: The effect of one bad apple on the barrel. Psychological Science, 20, 393-398. doi: 10.1111/j.1467-9280.2009.02306.x

Govorun, O., \& Payne, B. K. (2006). Ego-depletion and prejudice: Separating automatic and controlled components. Social Cognition, 24, 111-136. doi: 10.1521/soco.2006.24.2.111

Hagger, M. S., \& Chatzisarantis, N. L. D. (2016). A multilab preregistered replication of the egodepletion effect. Perspectives on Psychological Science, 11, 546-573. doi: $10.1177 / 1745691616652873$

Hagger, M. S., Wood, C., Stiff, C., \& Chatzisarantis, N. L. D. (2010). Ego depletion and the strength model of self-control: A meta-analysis. Psychological Bulletin, 136, 495-525. doi: $10.1037 / \mathrm{a} 0019486$

Heatherton, T. F., \& Wagner, D. D. (2012). Cognitive neuroscience of self-regulation. Trends in Cognitive Science, 15, 132-139. doi: 10.1016/j.tics.2010.12.005

Helzer, E. G., \& Pizarro, D. A. (2011). Dirty liberals! Reminders of physical cleanliness influence moral and political attitudes. Psychological Science, 517-522.

Hodson, G., \& Costello, K. (2007). Interpersonal disgust, ideological orientations, and dehumanization as prejudice of intergroup attitudes. Psychological Science, 18, 691-698. doi: 10.1111/j.1467-9280.2007.01962.x 
Hofmann, W., Vohs, K. D., \& Baumeister, R. F. (2012). What people desire, feel conflicted about, and try to resist in everyday life. Psychological Science, 23, 582-588. doi: $10.1177 / 0956797612437426$

Huang, J. Y., Sedlovskaya, A., Ackerman, J. M., \& Bargh, J. A. (2011). Immunizing against prejudice: Effects of disease protection on attitudes toward out-groups. Psychological Science, 22, 1550-1556. doi: 10.1177/0956797611417261

Inzlicht, M., \& Schmeichel, B. J. (2012). What is ego-depletion? Toward a mechanistic revision of the resource model of self-control. Psychological Science, 7, 450-463. doi: $10.1177 / 174569161254134$

Kallgren, C. A., Reno, R. R., \& Cialdini, R. B. (2000). A focus theory of normative conduct: When norms do and do not affect behavior. Personality and Social Psychology Bulletin, 26, 1002-1012. doi: 10.1177/01461672002610009

Lee, S. W. S., \& Schwarz, N. (2010). Dirty hands and dirty mouths: Embodiment of the moralpurity metaphor is specific to the motor modality involved in moral transgression. Psychological Science, 21, 1423-1425. doi: 10.1177/0956797610382788

Legault, L., Green-Demers, I., \& Eadie, A. L. (2009). When internalization leads to automatization: The role of self-determination in automatic stereotype suppression and implicit prejudice regulation. Motivation and Emotion, 33, 10-24. doi: 10.1007/s11031008-9110-4

Monteith, M. J. (1993). Self-regulation of prejudiced responses: Implications for progress in prejudice-reduction efforts. Journal of Personality and Social Psychology, 65, 469-485. doi: 10.1037/0022-3514.65.3.469 
Monteith, M. J., Ashburn-Nardo, L., Voils, C. I., \& Czopp, A. M. (2002). Putting the brakes on prejudice: On the development and operation of cues for control. Journal of Personality and Social Psychology, 83, 1029-1050. doi: 10.1037//0022-3514.83.5.1029

Monteith, M. J., Deneen, N. E., \& Tooman, G. D. (1996). The effect of social norm activation on the expression of opinions concerning gay men and blacks. Basic and Applied Social Psychology, 18, 267-288. doi: 10.1207/s15324834basp1803_2

Muraven, M. (2008). Prejudice as self-control failure. Journal of Applied Social Psychology, 28, 314-333. doi: 10.1111/j.1559-1816.2007.00307.x

Muraven, M., \& Baumeister, R. F. (2000). Self-regulation and depletion of limited resources: Does self-control resemble a muscle? Psychological Bulletin, 126, 247-259. doi: $10.1037 / / 0033-2909.126 .2 .247$

Muraven, M., Tice, D. M., \& Baumeister, R. F. (1998). Self-control as limited resource: Regulatory depletion patterns. Journal of Personality and Social Psychology, 74, 774789. doi: $10.1037 / 0022-3514.74 .3 .774$

Plant, E. A. \& Devine, P. G. (1998). Internal and external motivation to respond without prejudice. Journal of Personality and Social Psychology, 75, 811-832. doi: $10.1037 / 0022-3514.75 .3 .811$

Schmeichel, B. J., \& Baummeister, R. F. (2004). Self-regulatory strength. In R F. Baumeister \& K. D. Vohs (Eds.), Handbook of self-regulation: Research, theory, and applications (pp. 84-98). Guilford Press: New York.

Schmeichel, B. J., Harmon-Jones, C., \& Harmon-Jones, E. (2010). Exercising self-control increases approach motivation. Journal of Personality and Social Psychology, 99, 162173. doi: $10.1037 / \mathrm{a} 0019797$ 
Schmeichel, B. J., \& Vohs, K. (2009). Self-affirmation and self-control: Affirming core values counteracts ego depletion. Journal of Personality and Social Psychology, 96, 770-782. doi: $10.1037 / \mathrm{a} 0014635$

Schultz, P. W., Nolan, J. M., Cialdini, R. B., Goldstein, N. J., \& Griskevicius, V. (2007). Constructive, destructive, and reconstructive power of social norms. Psychological Science, 18, 429-434. doi: 10.1111/j.1467-9280.2007.01917.x

Stangor, C., Sechrist, G. B., \& Jost, J. T. (2001). Changing racial beliefs by providing consensus information. Personality and Social Psychology Bulletin, 27, 486-496. doi: $10.1177 / 0146167201274009$

Tangney, J. P., Baumeister, R. F., \& Boone, A. L. (2004). High self-control predicts good adjustment, less pathology, better grades, and interpersonal success. Journal of Personality, 72, 271-324. doi: 10.1111/j.0022-3506.2004.00263.x

Tice, D. M., Baumeister, R. F., Shmueli, D., \& Muraven, M. (2007). Restoring the self: Positive affect helps improve self-regulation following ego depletion. Journal of Experimental Social Psychology, 43, 379-384. doi: 10.1016/j.jesp.2006.05.007

Wagner, D. D., Altman, M., Boswell, R. G., Kelley, W. M., \& Heatherton, T. F. (2013). Selfregulatory depletion enhances neural response to rewards and impairs top-down control. Psychological Science, 24, 2262-2271. doi: 10.1177/0956797613492985

Zuwerink, J. R., Devine, P. G., Monteith, M. J., \& Cook, D. A. (1996). Prejudice towards blacks: With and without compunction? Basic and Applied Social Psychology, 18, 131-150. 


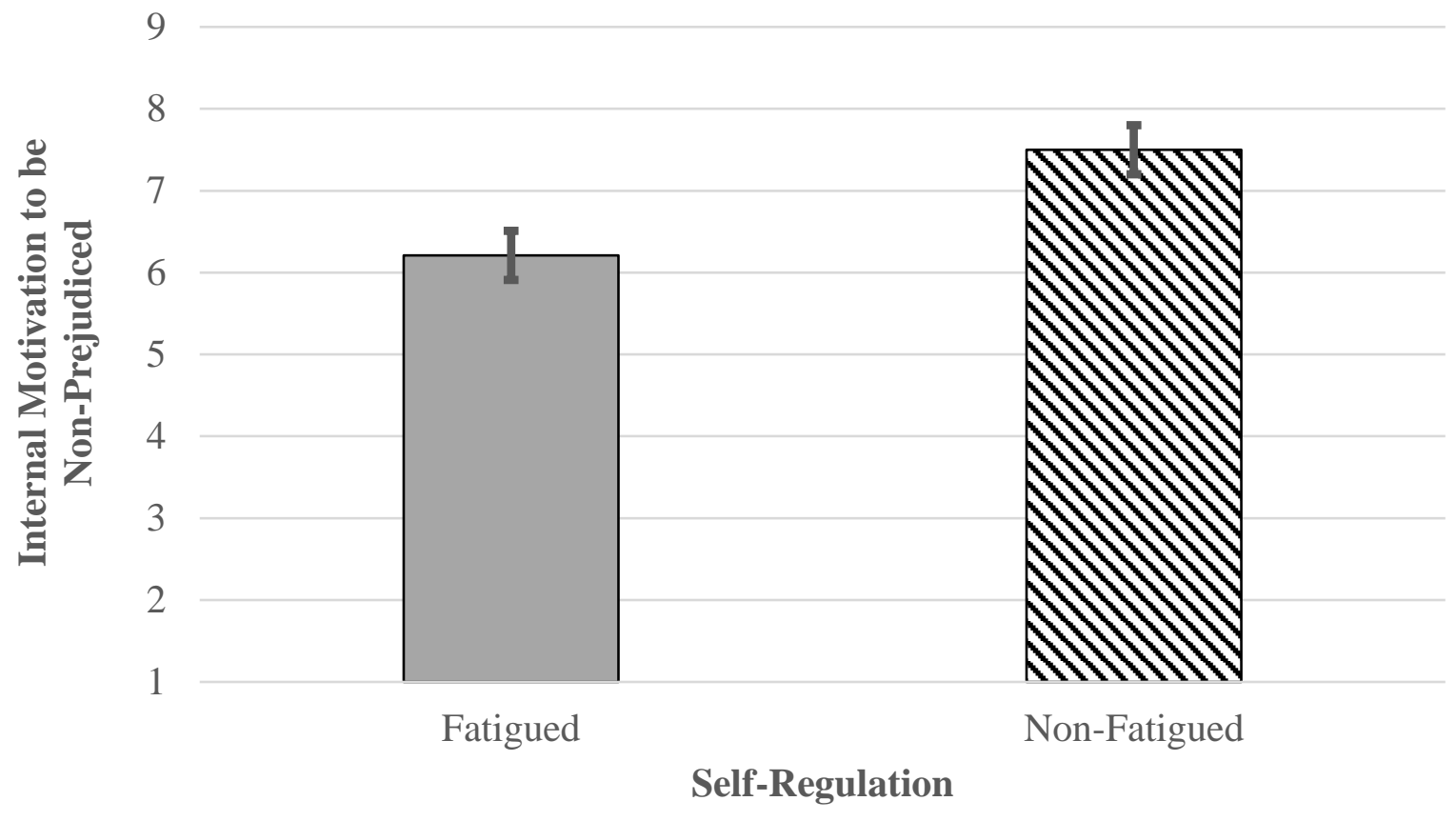

Figure 1. Participants' internal motivation to be non-prejudiced as a function of self-regulatory fatigue (Study 1). Bars indicate the estimated standard error. 


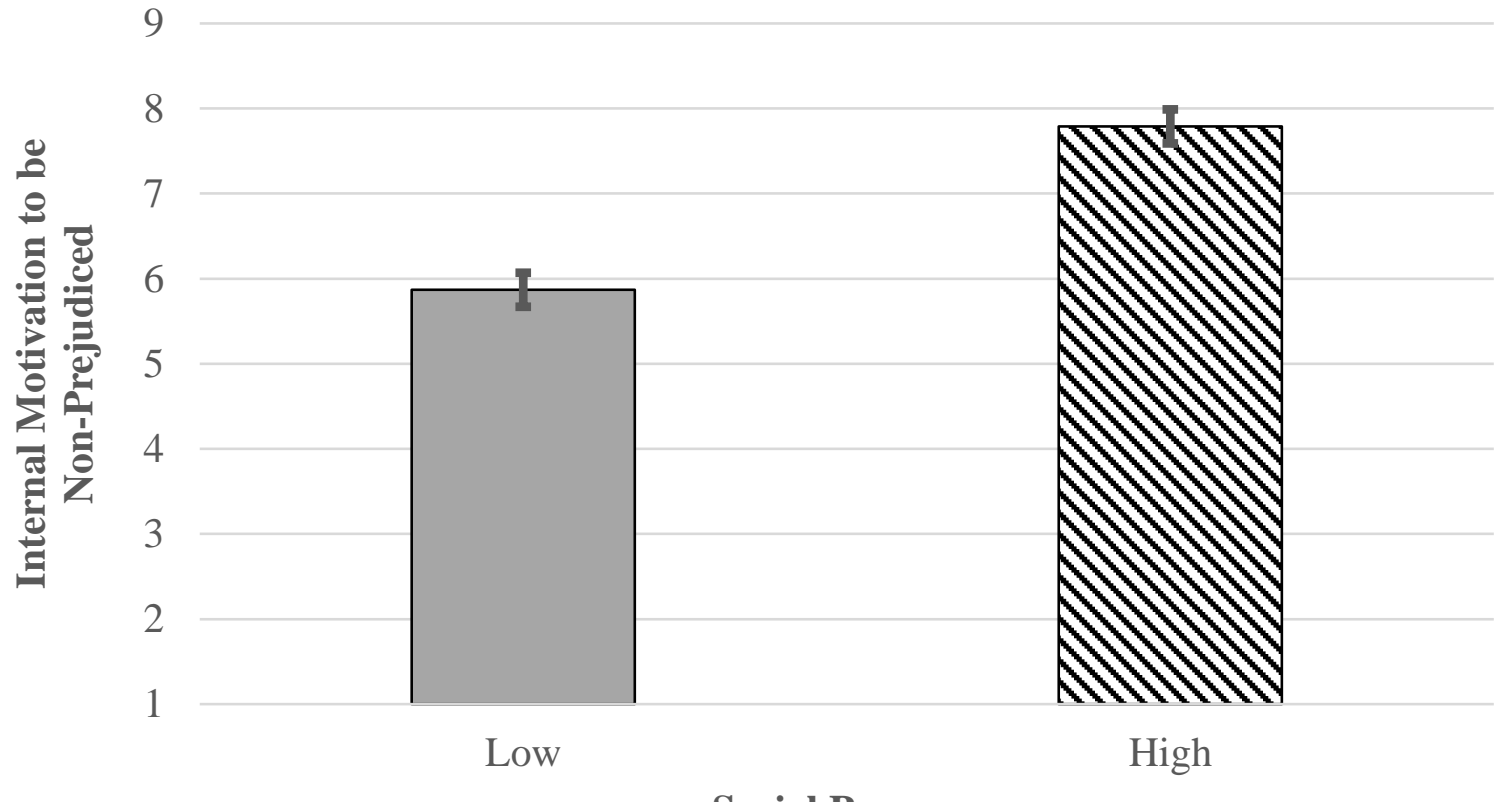

Social Pressure

Figure 2. Participants' internal motivation to be non-prejudiced as a function of perceived social pressure to be non-prejudiced (Study 2). Bars indicate the estimated standard error. 


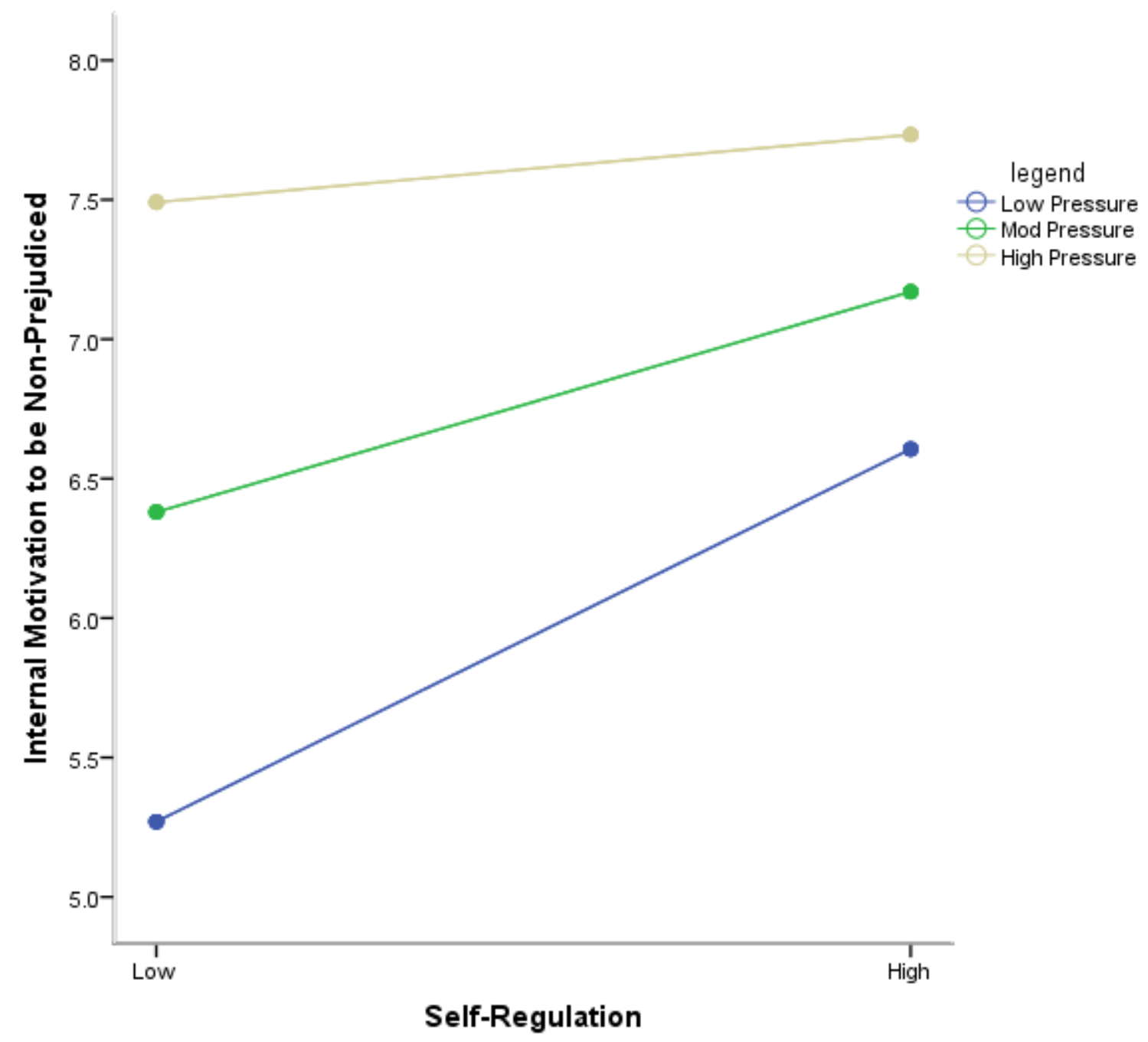

Figure 3. Association between dispositional self-regulation and internal motivation to be nonprejudiced at low, moderate, and high levels of perceived social pressure to be non-prejudiced (Study 3). 


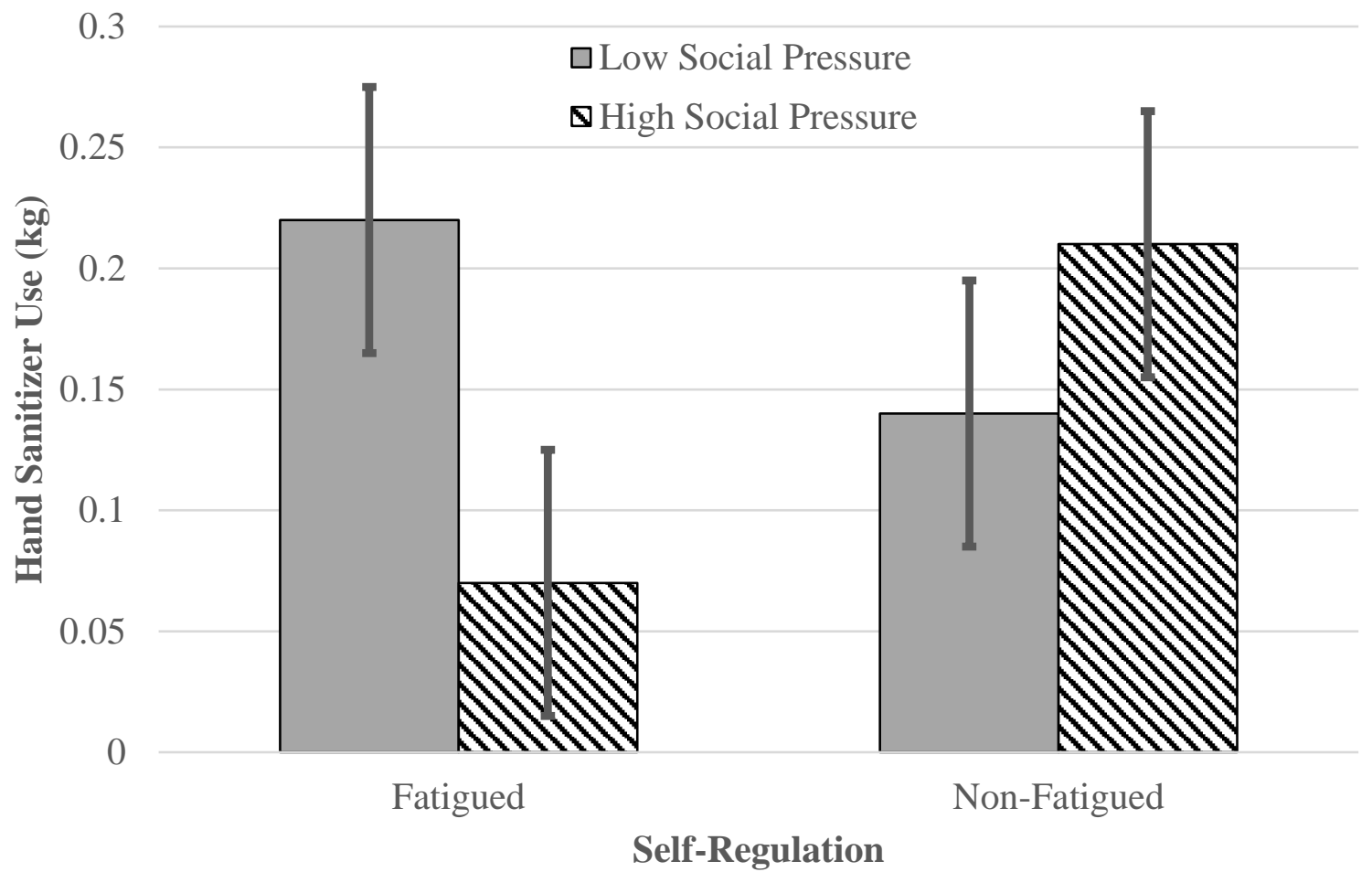

Figure 4. Participants' estimated mean use of hand-sanitizer as a function of self-regulatory fatigue and social pressure to be non-prejudiced, controlling for the number of cookies eaten (Study 4). Bars indicate the estimated standard error. 